\title{
A Feline Hemoplasma, 'Candidatus Mycoplasma haemominutum', Detected in Dog in Japan
}

\author{
Hisato OBARA ${ }^{1,2,3)}$, Masatoshi FUJIHARA ${ }^{1,3)}$, Yusaku WATANABE ${ }^{1,3)}$, Hisaya K. ONO ${ }^{3)}$ and Ryô HARASAWA ${ }^{1,3) *}$ \\ ${ }^{1)}$ Department of Veterinary Microbiology, School of Veterinary Medicine, Faculty of Agriculture, Iwate University, Morioka 020-8550, \\ ${ }^{2)}$ Will Animal Hospital, Sendai, Miyagi 983-0826 and ${ }^{3)}$ Department of Applied Veterinary Science, The United Graduate School of \\ Veterinary Sciences, Gifu University, Gifu 501-1193, Japan
}

(Received 22 November 2010/Accepted 14 January 2011/Published online in J-STAGE 28 January 2011)

ABSTRACT. We examined for 'Candidatus Mycoplasma haemominutum' infection in 167 blood samples collected from domestic dogs between 2008 and 2009 in the Tohoku area, Japan, and found $5(3.0 \%)$ were positive by PCR assay. This is the first demonstration of 'Candidatus Mycoplasma haemominutum', a feline haemotropic mycoplasma, in the dogs raised in Japan. KEY WORDS: 16S rRNA, canine, feline hemoplasma, mycoplasma.

J. Vet. Med. Sci. 73(6): 841-843, 2011

Hemoplasmas, hematropic mycoplasmas, infect the erythrocytes and are causative of hemolytic anemia and thrombocytosis in animal [16]. Currently, three hemoplasma species, Mycoplasma haemofelis, 'Candidatus Mycoplasma haemominutum', and 'Candidatus M. turicensis', and tentatively "Candidatus M. haematoparvum-like" strain are recognized in cats $[4,5,19,23]$. On the other hand, there are two hemoplasma species in dogs, $M$. haemocanis [15], and 'Candidatus M. haematoparvum' [18]. In general, the Mycoplasma species has the strict host specificity, so there have been only a few reports of the infections in an animal species not perceived as primary host.

The inability to culture the hemoplasma in vitro has hampered the possibilities of investigating the epidemiology and pathogenesis of this particular microbial agent [7]. Definitive diagnosis of hemoplasma infection has mainly been depend on microscopic examination of a thin WrightGiemsa-stained blood smear, but this method and has low sensitivity and specificity because the organisms resemble Howell-Jolly bodies or back ground debris [2], and it is more difficult to distinguish between hemoplasma species. Thus the PCR is widely used to detect hemoplasmas because of its sensitivity $[1,21]$.

Haemoplasmosis caused by $M$. haemofelis can lead to life-threatening hemolytic anemia in cats, whereas clinical signs in haemoplasmosis caused by 'Candidatus M. haemominutum' and 'Candidatus M. turicensis' have been reported to be minor or absent [5]. Dogs are latently infected with hemoplasmas, and the presence of underlying disorders such as immunosuppressive, co-infection, splenectomy, overt disease, trigger the anemia by hemoplasmas $[8,14,22]$.

Although there are a few epidemiological reports on

* Correspondence to: Harasawa, R., Department of Veterinary Microbiology, School of Veterinary Medicine, Faculty of Agriculture, Iwate University, Morioka 020-8550, Japan.

e-mail: harasawa-tky@umin.ac.jp
'Candidatus M. haemominutum' infections in dogs in only China [25] and France [12], there have been no examination on this particular hemoplasma species in Japan. Therefore, we examined for the presence of the feline hemoplasma 'Candidatus M. haemominutum' infection in the dogs in Japan.

Ethylene diamine-tetraacetic acid (EDTA)-anticoagulated blood samples were collected from 167 pet dogs (Canis lupus familiaris) in the Miyagi Prefecture, Japan between 2008 and 2009. The whole blood samples were taken for clinical diagnostic and health check purposes, and the remainder was subjected to detection of 'Candidatus M. haemominutum'. These dogs have no travel history and not been splenectomized. Date on age and sex and clinical information obtained for the dogs was incomplete. The contact history to the cats is unknown. Blood samples were stored at $-80^{\circ} \mathrm{C}$ prior to analysis.

DNA was extracted from $200 \mu l$ anticoagulated whole blood in EDTA collected using QIAamp DNA Blood Mini Kit (QIAGEN, Hilden, Germany) according to the manufacture's instructions. DNA was eluted in $200 \mu \mathrm{l}$ elution buffer and stored at $-20^{\circ} \mathrm{C}$ until examination in the PCR assay.

The 16S rRNA gene of 'Candidatus M. haemominutum' was amplified by using the following primers. A 654-bp fragment of the 16 rRNA gene was amplified using primers F1 (5'-GATTAATGCTGGTGGTATGC-3') and R1 (5'CATTGAATTCCAGTATCTCC-3') [6]. A 403-bp fragment of the 16 rRNA gene was amplified using primers F2 (5'-TACTCTCTTAGTGGCGAACG-3') and R2 (5'-AATCAAGGCTTAATCATTTC-3') [6]. PCR was performed in two steps as followed; the first with pairs of the outer primers (F1 and R1) and the second with the inner primers (F2 and R2). The mixture for each reaction contained $5 \mu l$ of extracted DNA samples and $45 \mu l$ of the PCR master mix, which consisted of $5 \mu l$ of 10X PCR buffer, $8 \mu l$ of $2.5 \mathrm{mM}$ deoxynucleoside triphosphates, 10 pmol specific outer primers, 2 units of Tth DNA polymerase (TOYOBO, Tokyo, Japan) and one drop of mineral oil. PCR was per- 
formed with an initial denaturation of $94^{\circ} \mathrm{C}$ for $30 \mathrm{sec}$, followed by 30 cycles of heating at $94^{\circ} \mathrm{C}$ for $30 \mathrm{sec}$, at $55^{\circ} \mathrm{C}$ for $2 \mathrm{~min}$, and at $72^{\circ} \mathrm{C}$ for $1 \mathrm{~min}$. Then $1 \mu l$ of the first PCR products were transferred into a second tube containing 49 $\mu l$ of the reaction buffer as described in the first round reaction, for the second round of the same 30 cycles of amplification, but with the pair of inner primers. The PCR products were detected by electrophoresis on a $1.0 \%$ agarose gel in Tris-acetate-EDTA buffer and stained with ethidium bromide $(0.4 \mu \mathrm{g} / \mathrm{ml})$ and visualized under UV transilluminator, BioDoc-I Imaging System (UVP, Upland, CA, U.S.A.). Positive samples were directly subjected to DNA sequencing for identification of hemoplasma species. The nucleotide sequence of the partial 16S rRNA gene has been deposited in the DDBJ, EMBL, GSDB and NCBI nucleotide sequence databases under the accession number AB550430.

A PCR product was amplified from the five dogs, with expected band size on a $1.0 \%$ agarose gel (Fig. 1). Three are adult dogs suffering from multi-centric lymphoma, starvation, atopic dermatitis, respectively. The other two dogs are puppy (about three months old) and have no sign of disease. No PCR products were amplified from the other 162 dogs, which did not develop any clinical sign of haemolytic anemia due to 'Candidatus M. haemominutum' infection. Comparison of the obtained sequence (a dog suffered from lymphoma) with those corresponding sequences available in the GenBank database revealed the $98 \%$ homology to the 16S rRNA gene of 'Candidatus M. haemominutum' (Fig. 2). We can not gain sequence of the other 4 PCR products because of insufficient PCR product in the first step PCR.

In this study, we first demonstrated that feline hemoplasma 'Candidatus M. haemominutum' infected dogs in the northern part of Japan. The relatively low prevalence in dogs in this study, as compared to the feline infection rate of 'Candidatus M. haemominutum' in Japan [6], may be based on the present study included healthy dog population. The study has certain limitations because of the relatively small number of case analyzed.

These dogs infected with hemoplasma had been kept in the ectoparasite-free conditions and no clinical signs of

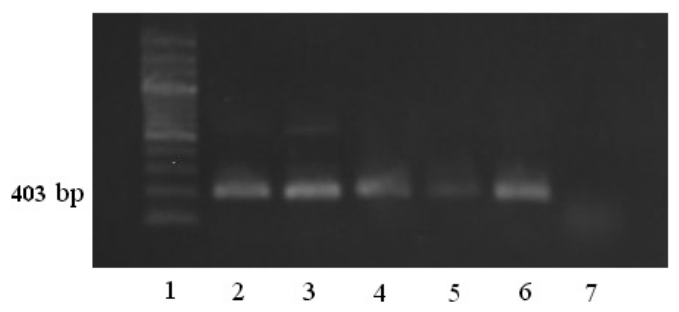

Fig. 1. A representative PCR result on detection for feline 'Candidatus M. haemominutum' in the dogs. Lane 1 shows 200-bp DNA Ladder (TaKaRa-Bio, Shiga, Japan); Lanes 2-6 show 403-bp DNA fragment. Lanes 2, 3 and 4 dogs suffered from multi-centric lymphoma, starvation, atopic dermatitis, respectively. Lanes 5 and 6; healthy puppy; Lane 7; negative control (water). hemolytic anemia by 'Candidatus M. haemominutum'. It is known that 'Candidatus M. haemominutum' infection rarely results in significant clinical signs and anemia is not usually apparent in cat [5]. Similarly, dogs infected with 'Candidatus M. haemominutum' lacked any clinical signs of hemolytic anemia. The pathogenicity of 'Candidatus M. haemominutum' may be not severe in the dogs.

The transmission route of 'Candidatus M. haemominutum' from the cats to the dog is currently unknown. Bloodsucking arthropods (e.g., flees, ticks) have been suspected as natural means of hemoplasma transmission [24]. However, there were not so much tick infestions due to the cold climate in the Tohoku area compared to the southern parts in Japan. It is also possible that the infection was occurred by horizontal transmission from infected cats. There is some

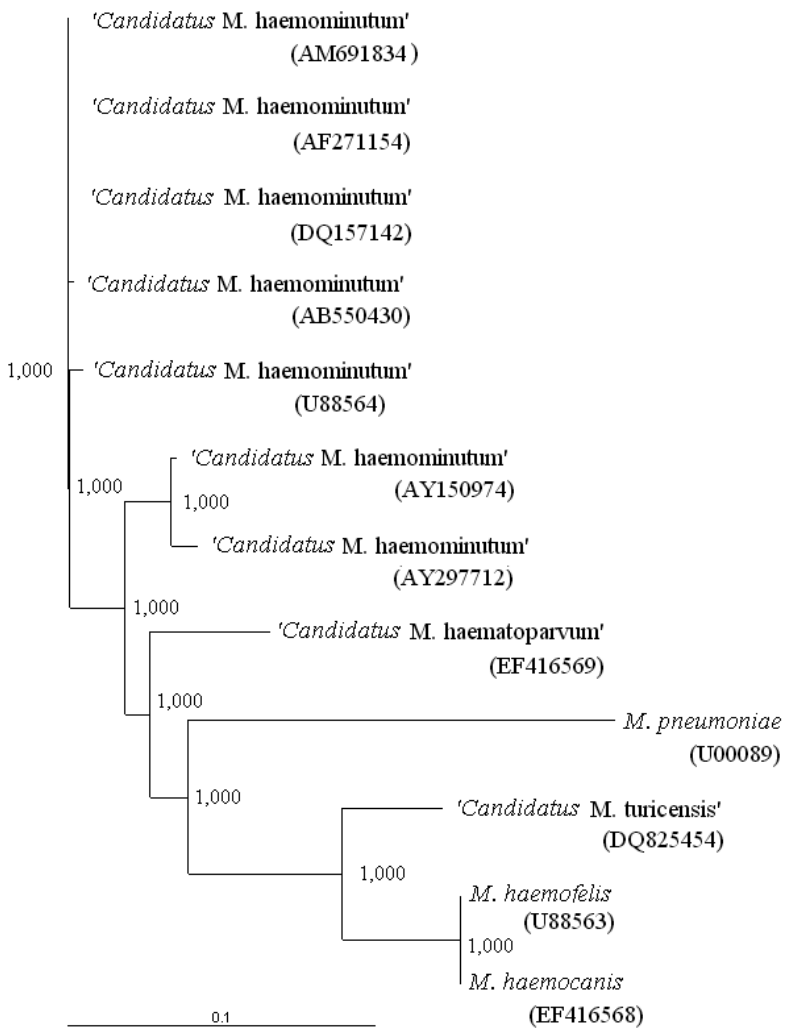

Fig. 2. Phylogenetic tree based on the 16S rRNA sequence comparison among feline and canine hemoplasmas. Genetic distances were computed with CLUSTAL W [14]. Hemoplasma sequences used in this analysis were as follows: 'Candidatus M. haematoparvum' (EF416569), 'Candidatus M. haemominutum '(AB550430, AF271154, AM691834, DQ157142, U88564, AY150974, AY297712), 'Candidatus M. turicensis' (DQ825454), M. haemocanis (EF416568), and M. haemofelis (U88563). Out-group unit was M. pnemoniae (U00089). Numbers in the relevant branches refer to the values of boot-strap probability of 1,000 replications. Scale bar indicates the evolutionary distance value of 0.1 (a single nucleotide substitution per 10 nucleotides). AB550430 represents a hemoplasma strain detected from a dog (suffered from multi-centric lymphoma) in the present study. 
evidence for direct transmission of hemoplasma in cat [24]. In dog, direct transmission of hemoplasmas is one the likely routes. There is also the possibility of transplacental infection [13]. Since we detected 'Candidatus M. haemominutum' from the two puppies of three months old, there is another likely route of the vertical transmission of 'Candidatus M. haemominutum' in dogs. The mechanisms of transmission of hemoplasma between dogs and cats have yet to be defined and need further exploration. Zhuang et al. [25] suggested the possibility that a dog was one of the hosts for the feline hemoplasma 'Candidatus M. haemominutum'. However, it is likely that the presence of some underlying conditions (e.g., immunosuppressive, immature) may destroy the strict host specificity in mycoplasma infections, as previously reported in the cases of hemoplasma infection in human $[3,10,11,17]$. Also, our results may indicate that dogs represent one of the hosts for the feline 'Candidatus M. haemominutum'.

In conclusion, we first showed feline hemoplasma ' $\mathrm{Can}$ didatus M. haemominutum' infected with dogs in Japan.

ACKNOWLEDGMENT. We thank Dr. Kou Chiba, the director of Will animal hospital, for the useful advice.

\section{REFERENCES}

1. Berent, L. M., Messick, J. B. and Cooper, S. K. 1998. Detection of Haemobartonella felis in cats with experimentally induced acute and chronic infections, using a polymerase chain reaction assay. Am. J. Vet. Res. 59: 1215-1220.

2. Bobade, P. A., Nash, A. S. and Rogerson, P. 1988. Feline haemobartonellosis: clinical, haematological and pathological studies in natural infections and the relationship to infection with feline leukaemia virus. Vet. Rec. 122: 32-36.

3. Duarte, M. I., Oliveira, M. S., Shikanai-Yasuda, M. A., Mariano, O. N., Takakura, C. F., Pagliari, C. and Corbett, C. E. 1992. Haemobartonella-like microorganism infection in AIDS patients: ultrastructural pathology. J. Infect. Dis. 165: 976-977.

4. Flint, J. C., Roepke, M. H. and Jensen, R. 1959. Feline infections anemia. II. Experimental cases. Am. J. Vet. Res. 20: $33-$ 40.

5. Foley, J. E. and Pedersen, N. C. 2001. 'Candidatus Mycoplasma haemominutum', a low-virulence epierythrocytic parasite of cats. Int. J. Syst. Evol. Microbiol. 51: 815-817.

6. Fujihara, M., Watanabe, M., Yamada, T. and Harasawa, R. 2007. Occurrence of 'Candidatus Mycoplasma turicensis' infection in domestic cats in Japan. J. Vet. Med. Sci. 69: 10611063.

7. Harvey, J. W. 1998. pp. 166-171. In: Infectious Diseases of the Dog and Cat (Greene, C.E. ed.), WB Saunders, Philadelphia.

8. Hoskins, J. D. 1991. Canine haemobartonellosis, canine hepatozoonosis, and feline cytauxzoonosis. Vet. Clin. North Am. Small Anim. Pract. 21: 129-140.

9. Hu, Z., Yin, J., Shen, K., Kang, W. and Chen, Q. 2009. Outbreaks of hemotrophic mycoplasma infections in China. Emerg. Infect. Dis. 15: 1139-1140.

10. Kallick, C. A., Levin, S., Reddi, K. T. and Landau, W. L. 1972. Systemic lupus erythematosus associated with haemobartonella-like organisms. Nat. New Biol. 236: 145-146.

11. Kallick, C. A., Thadhani, K. C. and Rice, T. W. 1980. Identifi- cation of Anaplasmataceae (Haemobartonella) antigen and antibodies in systemic lupus erythematosus. Arthritis Rheum. 23: 197-205.

12. Kenny, M. J., Shaw, S. E., Beugnet, F. and Tasker, S. 2004. Demonstration of two distinct hemotropic mycoplasmas in French dogs. J. Clin. Microbiol. 42: 5397-5399.

13. Krakowka, S. 1977. Transplacentally acquired microbial and parasitic diseases of dogs. J. Am. Vet. Med. Assoc. 171: 750 753.

14. Lester, S. J., Hume, J. B. and Phipps, B. 1995. Haemobartonella canis infection following splenectomy and transfusion. Can. Vet. J. 36: 444-445.

15. Messick, J. B. 2003. New perspectives about hemotrophic mycoplasma (formerly, Haemobartonella and Eperythrozoon species) infections in dogs and cats. Vet. Clin. North Am. Small Anim. Pract. 33: 1453-1465.

16. Messick, J. B. 2004. Hemotrophic mycoplasmas (hemoplasmas): a review and new insights into pathogenic potential. Vet. Clin. Pathol. 33: 2-13.

17. Santos, A. P., Santos, R. P., Biondo, A. W., Dora, J. M., Goldani, L. Z., de, Oliveira, S. T., de, Sa, Guimaraes, A. M., Timenetsky, J., de, Morais, H. A., Gonzalez, F. H. and Messick, J. B. 2008. Hemoplasma infection in HIV-positive patient, Brazil. Emerg. Infect. Dis. 14: 1922-1924.

18. Sykes, J. E., Bailiff, N. L., Ball, L. M., Foreman, O., George, J. W. and Fry, M. M. 2004. Identification of a novel hemotropic mycoplasma in a splenectomized dog with hemic neoplasia. $J$. Am. Vet. Med. Assoc. 224: 1946-1951, 1930-1931.

19. Sykes, J. E., Drazenovich, N. L., Ball, L. M. and Leutenegger, C. M. 2007. Use of conventional and real-time polymerase chain reaction to determine the epidemiology of hemoplasma infections in anemic and nonanemic cats. J. Vet. Intern. Med. 21: 685-693.

20. Thompson, J. D., Higgins, D. G. and Gibson, T. J. 1994. CLUSTAL W: improving the sensitivity of progressive multiple sequence alignment through sequence weighting, positionspecific gap penalties and weight matrix choice. Nucleic Acids Res. 22: 4673-4680.

21. Watanabe, M., Hisasue, M., Souma, T., Ohshiro, S., Yamada, T. and Tsuchiya, R. 2008. Molecular detection of Mycoplasma haemofelis and 'Candidatus Mycoplasma haemominutum' Infection in cats by direct PCR using whole blood without DNA extraction. J. Vet. Med. Sci. 70: 1095-1099.

22. Wengi, N., Willi, B., Boretti, F. S., Cattori, V., Riond, B., Meli, M. L., Reusch, C. E., Lutz, H. and Hofmann-Lehmann, R. 2008. Real-time PCR-based prevalence study, infection follow-up and molecular characterization of canine hemotropic mycoplasmas. Vet. Microbiol. 126: 132-141.

23. Westfall, D. S., Jensen, W. A., Reagan, W. J., Radecki, S. V. and Lappin, M. R. 2001. Inoculation of two genotypes of Hemobartonella felis (California and Ohio variants) to induce infection in cats and the response to treatment with azithromycin. Am. J. Vet. Res. 62: 687-691.

24. Willi, B., Boretti, F. S., Tasker, S., Meli, M. L., Wengi, N., Reusch, C. E., Lutz, H. and Hofmann-Lehmann, R. 2007. From Haemobartonella to hemoplasma: molecular methods provide new insights. Vet. Microbiol. 125: 197-209.

25. Zhuang, Q. J., Zhang, H. J., Lin, R. Q., Sun, M. F., Liang, X. J., Qin, X. W., Pu, W. J. and Zhu, X. Q. 2009. The occurrence of the feline "Candidatus Mycoplasma haemominutum" in dog in China confirmed by sequence-based analysis of ribosomal DNA. Trop. Anim. Health Prod. 41: 689-692. 